University of Nebraska - Lincoln

DigitalCommons@University of Nebraska - Lincoln

Library Philosophy and Practice (e-journal)

Libraries at University of Nebraska-Lincoln

August 2013

\title{
Glaucoma Research: A Scientometric Study of Indian Publications Output, 2002-11
}

Brij Mohan Gupta

National Institute of Science, Technology and Development Studies (NISTADS), New Delhi

Adarsh Bala

Government Medical College \& Hospital, Sector 32, Chandigarh. (India), adarshbindu@rediffmail.com

Follow this and additional works at: https://digitalcommons.unl.edu/libphilprac

Part of the Library and Information Science Commons

Gupta, Brij Mohan and Bala, Adarsh, "Glaucoma Research: A Scientometric Study of Indian Publications Output, 2002-11" (2013). Library Philosophy and Practice (e-journal). 939.

https://digitalcommons.unl.edu/libphilprac/939 
Glaucoma Research: A Scientometric Study of Indian Publications Output, 2002-11

\author{
B.M.Gupta* and Adarsh Bala** \\ *National Institute of Science, Technology \& Development Studies, \\ New Delhi 110012 \\ bmgupta1@gmail.com \\ **Government Medical College \& Hospital, \\ Sector 32, Chandigarh \\ adarshbindu@rediffmail.com
}

\begin{abstract}
Objectives: Analyses the Indian publications output in glaucoma research during 2002-11 on several parameters including contribution \& citation impact of top most productive countries, India's overall contribution, its growth pattern and citation impact, the share of international collaboration in India's overall research output, contribution of leading countries and identification of leading foreign collaborating partners, Indian contribution \& impact of different types of glaucoma, glaucoma research by sub-fields and glaucoma research output by different population age groups, productivity and impact of leading Indian institutions and authors and pattern of communication of Indian output in most productive journals.
\end{abstract}

Methods: The Scopus Citation Database has been used to retrieve the data for 10 years (2002-11) by searching the keywords "glaucoma or intraocular pressure" in combined Title, Abstract and Keywords field.

Results: The Indian publications output in glaucoma research consisted of 1078 papers during 2002-11, which increased from 61 papers in 2002 to 207 papers in 2011, witnessing an annual average growth rate of $18.29 \%$. The average citation impact per paper registered by Indian publications in glaucoma research was 3.03 during 2002-11, which decreased from 3.87 during 2002-06 to 2.49 during 2007-11. The international collaborative share of India in overall glaucoma research was $21.06 \%$ during 2002-11, which increased from $17.92 \%$ during $2002-06$ to $23.09 \%$ during $2007-11$

Conclusions: The glaucoma's irreversibility, lacking of glaucoma specialists and patients unawareness demand for an economic and effective glaucoma diagnosis system for screening. Disease control and elimination require an adequately trained functional workforce with an enabling infrastructure and technology.

Key Words: Glaucoma research, publications, India, scientometrics 


\section{Introduction}

The term "glaucoma" covers a number of different eye conditions, all of which involve damage to the optic nerve. One common cause is that there is too much pressure inside the eye. This pressure is called intraocular pressure. Intraocular pressure is caused by a fluid called aqueous humor produced by the eye itself in the chambers of the eye between the cornea and the lens. If the aqueous humor is prevented from draining properly, it starts to collect and pressure within the eye builds up. This presses against the optic nerve and there is a risk that nerve cells die. Whether the increased intraocular pressure does cause damage depends on, among other things, how well the optic nerve can resist this pressure. Intraocular pressure is measured in $\mathrm{mm} \mathrm{Hg}$ (millimeters of mercury), the same unit used for blood pressure. Readings between 10 and $21 \mathrm{~mm} \mathrm{Hg}$ are considered normal. Someone who has glaucoma does not always have above-average intraocular pressure ${ }^{1}$.

There is different type of glaucoma: (i) Open-angle glaucoma (also called primary or chronic glaucoma), caused by the slow clogging of the drainage canals, resulting in increased eye pressure. It is most common form of glaucoma, accounting for at least 90\% of all glaucoma; (ii) Angle-closure glaucoma, caused by blocked drainage canals, resulting in a sudden rise in intraocular pressure. It is a result of the angle between the iris and cornea closing. It is comparatively a less common form of glaucoma; (iii) Normal-tension glaucoma (also called low-tension or normal-pressure glaucoma) leads to the damage of optic nerve, even the eye pressure may not very high and (iv) Congenital Glaucoma (also called childhood glaucoma and for glaucoma diagnosed in infancy or early childhood), caused by abnormal intraocular fluid drainage from the eye as a result of a blocked or defective trabecular meshwork. It may be due to hereditary defect or abnormal development during pregnancy. In other cases, an abnormal drainage system may be the result of some other disease in the eye which results in secondary glaucoma ${ }^{2}$.

Most other types of glaucoma are variations of open-angle or angle-closure types: (a) Secondary glaucoma: Here disease contributes to increased eye pressure, resulting in optic nerve damage and vision loss or may occur as the result of an eye injury, inflammation, tumor, or in advanced cases of cataract or diabetes or it can also be caused by certain drugs such as steroids; (b) Pigmentary Glaucoma: It occurs when the pigment granules that are in the back of the iris (the colored part of the eye) break into the clear fluid produced inside the eye And causes eye pressure to rise; (c) Pseudoexfoliative Glaucoma - It occurs when a flaky, dandruff-like material peels off the outer layer of the lens within the eye. The material collects in the angle between the cornea and iris and can clog the drainage system of the eye, causing eye pressure to rise; (d) Traumatic Glaucoma - Injury to the eye immediately or years later may cause traumatic glaucoma. It can be caused by blunt injuries that bruise the eye (called blunt trauma) or by injuries that penetrate the eye; (e) Neovascular Glaucoma -The abnormal formation of new blood vessels on the iris and over the eye's drainage channels can cause asuch a glaucoma. The new blood vessels block the eye's fluid from exiting through the trabecular meshwork (the eye's drainage canals), causing an increase in eye 
pressure It is always associated with other abnormalities, most often diabetes. It never occurs on its own. and ; (f) Irido Corneal Endothelial Syndrome (ICE) - Cells on the back surface of the cornea spread over the eye's drainage tissue and across the surface of the iris, increasing eye pressure and damaging the optic nerve. These corneal cells also form adhesions that bind the iris to the cornea, further blocking the drainage channels ${ }^{3}$.

Glaucoma affects about 70 million people worldwide, of whom about 10 per cent are believed to be bilaterally blind. It is estimated that by the year 2020, this number would rise to around 79.6 million. Statistics gathered by the World Health Organization (WHO) show that glaucoma is the second leading cause of blindness globally, after cataract. Glaucoma, however, presents greater health challenge than cataract because the blindness it causes is irreversible. India has the third largest number of glaucoma patients, after China and Europe/USA. Glaucoma is the third leading cause of blindness in India, but the alarming thing is that by the time a patient is detected to be having glaucoma, $90 \%$ have lost $50 \%$ of their sight In India, it is estimated that glaucoma affects 12 million people accounting for $12.8 \%$ of the countries blindness and by 2020; this is expected to be 16 million. Population based studies report a prevalence between 2 to $13 \%$ in India. In India, more than 90 per cent of glaucoma in the community is undiagnosed. Statistics say one in eight persons above the age of 40 years in India is either suffering from glaucoma or is at risk of the disease. Glaucoma can affect any age group, including newborn, infants, children and elderly6.

Glaucoma Society of India was established in 1990 with the aim of disseminating current practice patterns and help ophthalmologists in different parts India upgrade their skills to promote excellence in patent care and help preserve their vision related quality of life. It also organizes nation wide glaucoma courses in order to spread basic as well as updated knowledge of glaucoma diagnosis and management meant for all ophthalmologists: private practitioners, ophthalmologists in private or government teaching institutions and all residents/postgraduates ${ }^{7}$.

Few studies were conducted on country distribution of ophthalmology and visual science literature. Davies, Wilson \& Hood $^{8}$ studied Australia's contribution to vision science domain literature during 1991-95, using ISI's SCI, SSCI, \& AHCI databases. Zou, Wu \& Wu' analyzed 961 ophthalmology, optometry and visual science publications of China, using SCI database during 2000-2007. Kumaragurupari, Sieving \& Lalitha ${ }^{10}$ analyzed 2163 publications by Indian ophthalmologists and vision researchers during 2001-2006, with a view access their productivity, analyze trends in journal choice, publication types, research funding and collaborative research. Publications resulting from international collaborations increased from 3\% in 2001 to $8 \%$ in 2006. The major focus of Indian publications was on cataract and clinical science articles were most frequently published whereas basic science the least. Only one scientometric study could be identified on glaucoma. Consoli and Ramgoplan ${ }^{11}$ analyzed 9361 world glaucoma papers published during 1973-2003 appearing in ISI Thompson database. The research output was classified into 26 sub-areas and 5 broad 
areas. The authors searched glaucoma in the Topic Field-which includes title, keywords and abstract using institutional addresses of authors as a guide to study intra-organizational and inter-organizational collaboration across research units, health care delivering units and firms.

\section{Objectives}

The main objective of this study is to analyze the Indian research output in glaucoma during 2002-11. The study has the following objectives: (i) To study the contribution \& citation impact of top 15 most productive countries, (ii) To study the India's overall contribution, its growth pattern and citation impact, (iii) to study the share of international collaboration in India's overall research output, contribution of leading countries and identification of leading foreign collaborating partners; (iv) To study Indian contribution \& impact of different types of glaucoma, glaucoma research by sub-fields and glaucoma research output by different population age groups, (iv) To study the productivity and impact of leading Indian institutions and authors and (v) To study the pattern of communication of Indian output in most productive journals.

\section{Methodologies and Source of Data}

This study used Scopus International Database [http://www.scopus.com/search/] to extract relevant data on glaucoma research of world and other 15 most productive countries for the 10 years (2002-11). An advanced search strategy involving "glaucoma or intraocular pressure" as the keywords were used to search and download data using Title, Abstract and Keywords field, resulting in downloading of 1078 records related to Indian glaucoma research. Separate strategies were developed in terms of keywords for identifying different type of glaucoma research and glaucoma research output by different population age groups. For identifying conjunctivitis research by sub-fields, database classification as provided in Scopus database has been used. For analyzing significant institutions, authors and journals, separate search strategies were developed, which later combined with the main string lead to the generation of the desired output. For citations data, three years, two years, one year and zero year citation windows have been used for computing average citations per paper in conjunctivitis research during 2002-08, 2009, 2010 and 2011. For example, for papers published in 2002, citation window is three years from 2002-05. For papers published in 2009, citation window is two years from 2009-2011 and for papers published in 2010 citation window is one year 2010-11.

\section{Analyses}

\section{Global Publications Output and Citation Impact}

The global publication share of the top 15 most productive countries in glaucoma research varies from $1.39 \%$ to $27.25 \%$ during 2002-11. The United States tops the list, with a share of 27.25\% during 2002-11. The China and United Kingdom ranks second and third (with $8.60 \%$ and $8.09 \%$ share), followed by Japan and Germany ranking at $4^{\text {th }}$ to $5^{\text {th }}$ position with publications share of $6.75 \%$ and $6.36 \%$ respectively. India, 
Italy, Australia and Canada ranks at $6^{\text {th }}$ to $9^{\text {th }}$ positions (their global publications share ranging from $3.09 \%$ to $3.26 \%$ ). Turkey, Spain, France, Brazil, Switzerland and South Korea ranks at $10^{\text {th }}$ to $15^{\text {th }}$ positions (their global publications share ranging from $1.39 \%$ to $2.79 \%$ ) (Table 1).

The developed countries showing increase in their publications share are Spain by $1.08 \%$, followed by Australia.(0.77\%), Turkey (0.39\%), Italy (0.35\%), Canada (0.27\%) and Switzerland (0.07\%) from 2002-06 to 2007-11. In contrast, the developed countries showing decrease in their publications share during the same period are USA by $2.38 \%$, Japan (2.08\%), Germany (1.64\%), U.K.(0.76\%) and France (0.61\%). All developing countries have shown rise in their publications share in glaucoma research: China by $6.80 \%$, followed by South Korea (1.06\%), India (0.45\%) and Brazil (0.35\%) from 2002-06 to 2007-11 (Table 1).

India ranks at $6^{\text {th }}$ position among the top 15 most productive countries in glaucoma research with its global publications share of $3.26 \%$ during 2002-11. China and Brazil ranked at $2^{\text {nd }}$ and $13^{\text {th }}$ positions, with global publications share of $8.60 \%$ and $2.16 \%$, respectively during 2002-11. India's global publications share increased from $3.00 \%$ to $3.45 \%$ from 2002-06 to 2007-11. China and Brazil's global publications share increased from $4.71 \%$ to $11.51 \%$ and $1.96 \%$ to $2.31 \%$ from $2002-06$ to $2007-11$ (Table 1).

Considering the quality of papers published by these 15 most productive countries in terms of citation per paper which varies from 2.24 to 8.59 during 2002-11. The highest citation impact is registered by Italy with 8.59 citations per paper, followed by USA (7.91 citations per paper), Canada (7.48 citations per paper), Australia (7.40 citations per paper), Germany (7.17), Switzerland (7.00 citations per paper), France (6.74 citations per paper) and U.K. (6.46 citations per paper). Brazil, South Korea and Spain scored the impact varying from 5.15 to 5.61 citations per paper. Japan, Turkey, India and China achieved the citations quality less than 5 citations per paper. (Table 1 )

Table 1. Publications Output, Share and Rank of Top 15 Countries in Glaucoma Research, 2002-11

\begin{tabular}{|c|l|c|c|c|c|c|c|c|c|}
\hline S.No & Country. & \multicolumn{3}{|c|}{ Number of Papers } & \multicolumn{3}{c|}{ Share of Papers } & $\begin{array}{c}\text { Total } \\
\text { Citations }\end{array}$ & ACPP \\
\cline { 3 - 10 } & & $2002-06$ & $2007-11$ & $2002-11$ & $\begin{array}{c}2002 \\
-06\end{array}$ & $\begin{array}{c}2007 \\
-11\end{array}$ & $\begin{array}{c}2002- \\
11\end{array}$ & $2002-11$ & $2002-11$ \\
& & & & 4019 & 28.61 & 26.23 & 27.25 & 71325 & 7.91 \\
\hline 1 & USA & 4050 & 4969 & 9.71 & 11.51 & 8.60 & 6371 & 2.24 \\
\hline 2 & China & 667 & 2180 & 2847 & 4.71 & 6.46 \\
\hline 3 & UK & 1206 & 1470 & 2676 & 8.52 & 7.76 & 8.09 & 17296 & 6.18 \\
\hline 4 & Japan & 1124 & 1111 & 2235 & 7.94 & 5.86 & 6.75 & 9344 & 4.17 \\
\hline 5 & Germany & 1033 & 1072 & 2105 & 7.30 & 5.66 & 6.36 & 15088 & 7.17 \\
\hline 6 & India & 424 & 654 & 1078 & 3.00 & 3.45 & 3.26 & 3667 & 3.40 \\
\hline 7 & Italy & 427 & 638 & 1065 & 3.02 & 3.37 & 3.22 & 9145 & 8.59 \\
\hline 8 & Australia & 376 & 649 & 1025 & 2.66 & 3.43 & 3.10 & 7588 & 7.40 \\
\hline 9 & Canada & 416 & 608 & 1024 & 2.94 & 3.21 & 3.09 & 7664 & 7.48 \\
\hline 10 & Turkey & 363 & 559 & 922 & 2.56 & 2.95 & 2.79 & 3706 & 4.02 \\
\hline 11 & Spain & 280 & 579 & 859 & 1.98 & 3.06 & 2.60 & 4425 & 5.15 \\
\hline 12 & France & 414 & 437 & 851 & 2.92 & 2.31 & 2.57 & 5738 & 6.74 \\
\hline
\end{tabular}




\begin{tabular}{|l|l|c|c|c|c|c|c|c|c|}
\hline 13 & Brazil & 278 & 438 & 716 & 1.96 & 2.31 & 2.16 & 4017 & 5.61 \\
\hline 14 & Switzerland & 230 & 320 & 550 & 1.62 & 1.69 & 1.66 & 3849 & 7.00 \\
\hline 15 & South Korea & 111 & 348 & 459 & 0.78 & 1.84 & 1.39 & 2523 & 5.50 \\
\hline \multicolumn{8}{|c|}{ ACPP=Average Citation Per Paper } \\
\hline
\end{tabular}

\section{India's Contribution, Citation Impact and International Collaboration}

India's contribution in glaucoma research has increased from 61 papers in 2002 to 207 papers in 2011, witnessing an annual average growth rate of $18.29 \%$. Its cumulative publications output has increased from 424 papers during 2002-06 to 654 papers during 2007-11, witnessing a growth rate of 54.24\%. The average citation per paper registered by India's research in glaucoma during 2002-11 was 3.03, which has decreased from 3.87 during 2002-06 to 2.49 during 2007-11. India has contributed $21.06 \%$ international collaborative papers share in glaucoma research during 2002-11, which has increased from $17.92 \%$ during 2002-06 to 23.09\% during 2007-11 (Table 2).

Table 2. India's Publications and International Collaborative Publications Output in Glaucoma Research, 2002-11

\begin{tabular}{|c|c|c|c|c|c|}
\hline $\begin{array}{c}\text { Publication } \\
\text { Year }\end{array}$ & $\mathrm{TP}$ & $\mathrm{TC}$ & ACPP & ICP & $\%$ ICP \\
\hline 2002 & 61 & 182 & 2.98 & 7 & 11.48 \\
\hline 2003 & 89 & 344 & 3.87 & 13 & 14.61 \\
\hline 2004 & 82 & 315 & 3.84 & 16 & 19.51 \\
\hline 2005 & 98 & 381 & 3.89 & 27 & 27.55 \\
\hline 2006 & 94 & 418 & 4.45 & 13 & 13.83 \\
\hline 2007 & 114 & 581 & 5.10 & 26 & 22.81 \\
\hline 2008 & 86 & 456 & 5.30 & 22 & 25.58 \\
\hline 2009 & 87 & 351 & 4.03 & 21 & 24.14 \\
\hline 2010 & 160 & 191 & 1.19 & 40 & 25.00 \\
\hline 2011 & 207 & 48 & 0.23 & 42 & 20.29 \\
\hline 2002-06 & 424 & 1640 & 3.87 & 76 & 17.92 \\
\hline $2007-11$ & 654 & 1627 & 2.49 & 151 & 23.09 \\
\hline $2002-11$ & 1078 & 3667 & 3.03 & 227 & 21.06 \\
\hline \multicolumn{6}{|c|}{$\begin{array}{c}\text { TP=Total Papers; } \mathrm{TC}=\text { Total Citations; } \mathrm{ACPP}=\text { Average } \\
\text { Citation Per Paper; ICP=International Collaborative } \\
\text { Papers }\end{array}$} \\
\hline
\end{tabular}

In all 45 countries participated in international collaboration with India in glaucoma research during 200211, of which contribution of top 14 countries are listed in Table 3. The largest contribution to international collaborative papers of India in glaucoma research comes from United States (with $50.22 \%$ share), followed by UK (21.59\% share), Singapore (7.05\% share), Germany (5.29\% share), Italy (3.08\% share), 
Brazil (2.64\% share), Netherlands (3.08\% share), China (2.64\% share), Israel (2.20\% share), Japan (2.20\% share), Canada, Malaysia and Switzerland (1.76\% share each) and Nepal (1.32\% share). The share of international collaboration has decreased in USA by $15.5 \%$, Israel by $2.63 \%$, Nepal by $1.97 \%$, Switzerland by $1.31 \%$, Italy by $1.30 \%$ and Japan by $0.64 \%$, as against increase by $20.59 \%$ in U.K., $4.66 \%$ in Singapore, $3.97 \%$ in Brazil, 2.65\% each in Malaysia and Canada, $2.01 \%$ in Germany, $1.99 \%$ in China and $0.68 \%$ in Netherlands from 2002-06 to 2007-11 (Table 3).

Table 3. Major International Collaborative Partners of India in Glaucoma Research, 2002-11

\begin{tabular}{|c|c|c|c|c|c|c|c|}
\hline \multirow[b]{2}{*}{ S.No } & \multirow{2}{*}{$\begin{array}{l}\text { Collaborating } \\
\text { Country }\end{array}$} & \multicolumn{3}{|c|}{ ICP } & \multicolumn{3}{|c|}{ \% ICP } \\
\hline & & $\begin{array}{l}02- \\
06\end{array}$ & $\begin{array}{l}07- \\
11\end{array}$ & $\begin{array}{l}02- \\
11 \\
\end{array}$ & 02-06 & 07-11 & 02-11 \\
\hline 1. & USA & 46 & 68 & 114 & 60.53 & 45.03 & 50.22 \\
\hline 2. & U.K. & 6 & 43 & 49 & 7.89 & 28.48 & 21.59 \\
\hline 3. & Singapore & 3 & 13 & 16 & 3.95 & 8.61 & 7.05 \\
\hline 4. & Germany & 3 & 9 & 12 & 3.95 & 5.96 & 5.29 \\
\hline 5. & Italy & 3 & 4 & 7 & 3.95 & 2.65 & 3.08 \\
\hline 6. & Brazil & 0 & 6 & 6 & 0.00 & 3.97 & 2.64 \\
\hline 7. & Netherlands & 2 & 5 & 7 & 2.63 & 3.31 & 3.08 \\
\hline 8. & China & 1 & 5 & 6 & 1.32 & 3.31 & 2.64 \\
\hline 9. & Israel & 3 & 2 & 5 & 3.95 & 1.32 & 2.20 \\
\hline 10 & Japan & 2 & 3 & 5 & 2.63 & 1.99 & 2.20 \\
\hline 11 & Canada & 0 & 4 & 4 & 0.00 & 2.65 & 1.76 \\
\hline 12 & Malaysia & 0 & 4 & 4 & 0.00 & 2.65 & 1.76 \\
\hline 13 & Switzerland & 2 & 2 & 4 & 2.63 & 1.32 & 1.76 \\
\hline \multirow[t]{2}{*}{14} & Nepal & 2 & 1 & 3 & 2.63 & 0.66 & 1.32 \\
\hline & Total* & 76 & 151 & 227 & 100.00 & 100.00 & 100.00 \\
\hline \multicolumn{8}{|c|}{ ICP =International Collaborative Papers } \\
\hline \multicolumn{8}{|c|}{$\begin{array}{l}\text { *Total collaborating papers of India. In all collaborating papers of India, } \\
\text { there are one or more foreign collaborating countries. As a result, the } \\
\text { combined output of } 14 \text { foreign collaborating countries listed above in } \\
\text { Indian international collaborative output will be more than its total } \\
\text { international collaborative papers }\end{array}$} \\
\hline
\end{tabular}

Among the international collaborative partners of India as reflected in its international collaborative papers in glaucoma research during 2002-11, the largest contribution (21 papers) comes from University of Melbourne, Australia, followed by John Hopkins Bloomberg School of Public Health, USA (12 papers), Queensland Eye Institute, Australia (11 papers), University of Queensland, Australia (11 papers), Singapore Eye Institute (10 papers), Singapore National Eye Center (9 papers), Marshfield Clinical Research Foundation, Marshfield, USA (9 papers), John Hopkins School of Medicine, USA (7 papers), University of California, San Diego, USA (7 papers), University of Heidelberg, Germany, etc. (Table 4).

Table 4. Foreign Collaborating Centers with India along with their Output in Glaucoma Research, 2002-11

\begin{tabular}{|l|l|l|}
\hline S.No & Name of Foreign Collaborating Organization & $\begin{array}{l}\text { Research } \\
\text { Output }\end{array}$ \\
\hline
\end{tabular}




\begin{tabular}{|l|l|l|}
\hline 1 & University of Melbourne, Australia & 21 \\
\hline 2 & John Hopkins Bloomberg School of Public Health, USA & 12 \\
\hline 3 & Queensland Eye Institute, Australia & 11 \\
\hline 4 & University of Queensland, Australia & 11 \\
\hline 5 & Singapore Eye Institute & 10 \\
\hline 6 & Singapore National Eye Center & 9 \\
\hline 7 & $\begin{array}{l}\text { Marshfield Clinical Research Foundation, Marshfield, } \\
\text { USA }\end{array}$ & 9 \\
\hline 8 & John Hopkins School of Medicine, USA & 7 \\
\hline 9 & University of California, San Diego, USA & 7 \\
\hline 10 & University of Heidelberg, Germany & 6 \\
\hline
\end{tabular}

\section{Different Types of Glaucoma Research}

Under different type of glaucoma research, the maximum publication output (214) of India during 2002-11 was on open angle glaucoma (with 19.85\% share), followed by closed angle glaucoma (142 papers, $13.17 \%$ share), congenital glaucoma (92 papers, $8.53 \%$ share), normal tension glaucoma (77 papers, $7.14 \%$ share), secondary glaucoma (54 papers, $5.01 \%$ share), neovascular glaucoma (29 papers, $2.69 \%$ share), traumatic glaucoma (12 papers, $1.11 \%$ share), pigmentary glaucoma (5 papers, $0.46 \%$ share), pseudoexfoliative glaucoma (2 papers, $0.19 \%$ share) and Irido Corneal Endothelial syndrome (1 paper, 0.09\% share). In terms of citation impact per paper, the maximum citation impact (7.88) during 2002-11 was in normal tension glaucoma, followed by congenital glaucoma (3.85), open angle glaucoma (3.79), closed angle glaucoma (3.41), secondary glaucoma (3.20), traumatic glaucoma (2.67), pigmentary glaucoma (2.40), neovascular glaucoma (1.83), pseudoexfoliative glaucoma (0.50) and Irido Corneal Endothelial syndrome (0.00) (Table $5)$.

Table 5. Indian Publication Output \& Citation Quality in Different Types of Glaucoma Research, 2002-11

\begin{tabular}{|l|c|c|c|}
\hline \multirow{2}{*}{ Type of Glaucoma Research } & \multicolumn{3}{|c|}{$2002-11$} \\
\cline { 2 - 4 } & TP & TC & ACPP \\
\hline Open Angle Glaucoma & 214 & 812 & 3.79 \\
\hline Closed Angle Glaucoma & 142 & 484 & 3.41 \\
\hline Congenital Glaucoma & 92 & 354 & 3.85 \\
\hline Normal Tension Glaucoma & 77 & 607 & 7.88 \\
\hline Secondary Glaucoma & 54 & 173 & 3.20 \\
\hline Neovascular Glaucoma & 29 & 53 & 1.83 \\
\hline Traumatic Glaucoma & 12 & 32 & 2.67 \\
\hline Pigmentary Glaucoma & 5 & 12 & 2.40 \\
\hline Pseudoexfoliative Glaucoma & 2 & 1 & 0.50 \\
\hline $\begin{array}{l}\text { Irido Corneal Endothelial } \\
\text { Syndrome }\end{array}$ & 1 & 0 & 0.00 \\
\hline Total of India & 1078 & & \\
\hline
\end{tabular}




\section{Glaucoma Research Output in Context of Different Subjects}

India's publication output in glaucoma research during 2001-11 has been published in context of 5 subjects (as reflected in database classification based on journal subject), with highest publications output coming from medicine (949 papers and $88.03 \%$ publications share), followed by pharmacology, toxicology \& pharmaceutics (117 papers and 10.85\% publications share), neurosciences (106 papers and 9.83\% publications share), biochemistry, genetics \& molecular biology (59 papers and 5.47\% publications share) and health profession (15 papers and $1.39 \%$ publications share). On analyzing the quality and impact of glaucoma research output under different subjects, it was found that biochemistry, genetics \& microbiology had scored the highest impact (4.12 citations per paper), followed by medicine (3.08 citations per paper), neurosciences (2.48 citations per paper), pharmacology, toxicology \& pharmaceutics ( 2.40 citations per paper) and health profession (2.27 citations per paper)(Table 6)

Table 6. Subject-Wise Break-up of Indian Publications in Glaucoma Research during 2002-11

\begin{tabular}{|l|c|c|c|c|}
\hline \multicolumn{1}{|c|}{ Subfields } & TP & TC & ACPP & $\%$ TP \\
\hline Medicine & 949 & 2921 & 3.08 & 88.03 \\
\hline $\begin{array}{l}\text { Pharmacology, Toxicology \& } \\
\text { Pharmaceutics }\end{array}$ & 117 & 281 & 2.40 & 10.85 \\
\hline Neurosciences & 106 & 263 & 2.48 & 9.83 \\
\hline $\begin{array}{l}\text { Biochemistry, Genetics \& } \\
\text { Molecular Biology }\end{array}$ & 59 & 243 & 4.12 & 5.47 \\
\hline Health Profession & 15 & 34 & 2.27 & 1.39 \\
\hline Total* & 1078 & & & \\
\hline $\begin{array}{l}* \text { Total of India in glaucoma research. There is some overlapping of literature } \\
\text { under different sub-fields. As a result, the combined output of India under 5 sub- } \\
\text { fields will be more than its total research output }\end{array}$ \\
\hline
\end{tabular}

\section{Glaucoma Research by Population Age Groups}

The maximum focus of India glaucoma research in terms of research output during 2002-11 was on adults (539 papers and $50.00 \%$ share), followed by middle aged (300 papers and $27.83 \%$ share), adolescents (152 papers and $14.10 \%$ share) child (136 papers and $12.62 \%$ share) and aged $80 \&$ over (77 papers and $7.14 \%$ share). The focus of glaucoma research has increased in adults (from $47.17 \%$ to $51.83 \%$ ) and aged $80 \&$ over (from $5.19 \%$ to $8.41 \%$ ) from $2002-06$ to $2007-11$, as against decrease in middle aged (from $37.74 \%$ to $21.41 \%$ ), adolescents (from $16.27 \%$ to $12.69 \%$ ) and child (from $14.62 \%$ to $11.31 \%$ ) during the similar period (Table 7)

Table 7. Glaucoma Research Output by Different Age Group of Population, 2002-11

\begin{tabular}{|l|c|c|c|c|c|c|}
\hline Population by Age & \multicolumn{3}{|c|}{ Number of Papers } & \multicolumn{3}{c|}{ Percentage of Papers } \\
\cline { 2 - 7 } & $\begin{array}{c}2002- \\
06\end{array}$ & $2007-11$ & $2002-11$ & $2002-06$ & $2007-11$ & $2002-11$ \\
\hline
\end{tabular}




\begin{tabular}{|l|c|c|c|c|c|c|}
\hline Adults & 200 & 339 & 539 & 47.17 & 51.83 & 50.00 \\
\hline Middle Aged & 160 & 140 & 300 & 37.74 & 21.41 & 27.83 \\
\hline Adolescents & 69 & 83 & 152 & 16.27 & 12.69 & 14.10 \\
\hline Child & 62 & 74 & 136 & 14.62 & 11.31 & 12.62 \\
\hline Aged 80 \& Over & 22 & 55 & 77 & 5.19 & 8.41 & 7.14 \\
\hline Total & 424 & 654 & 1078 & 100.00 & 100.00 & 100 \\
\hline
\end{tabular}

There is some duplication in papers under different age groups. As a resulr, the total of papers by different age groups is slightly higher than actual total papers

\section{Research Profile of Most Productive Indian Institutions in Glaucoma Research}

The top 15 most productive Indian institutions involved in glaucoma research have published 11 and more papers each during 2001-11. The publications profile of these 15 Indian institutions along with their research output, citations received and h-index values are presented in Table 8. These 15 institutions involved in glaucoma research together have contributed $66.42 \%$ share (with 716 papers) in the cumulative world publications output in glaucoma research, with an average of 47.73 papers per institution. Only five institutions have registered higher publications share than the group average. These are All India Institute of Medical Sciences, Dr Rajendra Prasad Center for Ophthalmic Sciences, New Delhi with 209 papers, followed by L.V.Prasad Eye Institute, Hyderabad (174 papers), Post Graduate Institute of Medical Education \& Research, Chandigarh (55 papers), Vision Research Foundation, Chennai (50 papers) and Aravind Eye Hospital, Postgraduate Institute of Ophthalmology, Madurai (48 papers). The average citation per paper registered by the total papers of these 15 institutions is 3.55 during 2002-11. Only 5 Indian institutions have registered higher impact than the group average. Amongst these five Indian institutions, the highest impact of 8.63 citations per paper was scored by the Indian Institute of Chemical Biology, Kolkata, USA, followed by Vision Research Foundation, Chennai (6.26 citations per paper), Medical College \& Hospital, Kolkata (5.36 citations per paper), Medical Research Foundation, Chennai (4.43 citations per paper) and L.V.Prasad Eye Institute, Hyderabad (4.03 citations per paper). The average hindex value of these 15 most productive institutions was 8.80 during 2002-11. The six Indian institutions have scored higher h-index value than group's average of 8.80. Amongst these six Indian institutions, the highest h-index value (20) was achieved by All India Institute of Medical Sciences, Dr Rajendra Prasad Center for Ophthalmic Sciences, New Delhi and L.V.Prasad Eye Institute, Hyderabad, followed by Vision Research Foundation, Chennai (14), Post Graduate Institute of Medical Education \& Research, Chandigarh and Indian Institute of Chemical Biology, Kolkata (12 each) and Medical Research Foundation, Chennai (11).

Table 8. Productivity \& Citation Impact of Top Fifteen Major Indian Institutions in Glaucoma Research, 2002-11

\begin{tabular}{|c|l|c|c|c|c|}
\hline S.No. & Name & TP & TC & ACPP & $\begin{array}{c}\text { H- } \\
\text { Index }\end{array}$ \\
\hline 1 & $\begin{array}{l}\text { All India Institute of Medical Sciences, Dr } \\
\text { Rajendra Prasad Center for Ophthalmic Sciences, }\end{array}$ & 209 & 675 & 3.23 & 20 \\
\hline
\end{tabular}




\begin{tabular}{|c|l|c|c|c|c|}
\hline & New Delhi & & & & \\
\hline 2 & L.V.Prasad Eye Institute, Hyderabad & 174 & 701 & 4.03 & 20 \\
\hline 3 & $\begin{array}{l}\text { Post Graduate Institute of Medical Education \& } \\
\text { Research, Chandigarh }\end{array}$ & 55 & 154 & 2.80 & 12 \\
\hline 4 & Vision Research Foundation, Chennai & 50 & 313 & 6.26 & 14 \\
\hline 5 & $\begin{array}{l}\text { Aravind Eye Hospital, Postgraduate Institute of } \\
\text { Ophthalmology, Madurai }\end{array}$ & 48 & 70 & 1.46 & 8 \\
\hline 6 & Medical Research Foundation, Chennai & 47 & 208 & 4.43 & 11 \\
\hline 7 & Christian Medical College, Vellore & 21 & 67 & 3.19 & 7 \\
\hline 8 & Indian Institute of Chemical Biology, Kolkata & 19 & 164 & 8.63 & 12 \\
\hline 9 & $\begin{array}{l}\text { Government Medical College \& Hospital, } \\
\text { Chandigarh }\end{array}$ & 16 & 9 & 0.56 & 3 \\
\hline 10 & Maulana Azad Medical College, Delhi & 15 & 24 & 1.60 & 4 \\
\hline 11 & Medical College \& Hospital, Kolkata & 14 & 75 & 5.36 & 6 \\
\hline 12 & Bombay City Eye Institute \& Research Centre & 13 & 18 & 1.38 & 4 \\
\hline 13 & $\begin{array}{l}\text { Vardhman Mahavir Medical College \& } \\
\text { Safdarjung Hospital, New Delhi }\end{array}$ & 12 & 1.25 & 4 \\
\hline 14 & $\begin{array}{l}\text { Iladevi Cataract \& Intraocular Lens Research } \\
\text { Center, Ahmedabad }\end{array}$ & 12 & 39 & 3.25 & 5 \\
\hline 15 & Regional Institute of Ophthalmology, Kolkata & 11 & 13 & 1.18 & 2 \\
\hline & Total & 716 & 2545 & 3.55 & 8.8 \\
\hline & Total of the Country & 1078 & & & \\
\hline & $\begin{array}{l}\text { Share of Top 15 Institutions in Indian Output } \\
\text { TP =Total Papers; TC = Total Citations; ACPP = Average Citations Per Paper }\end{array}$ \\
\hline
\end{tabular}

\section{Contributions and Impact of Most Productive Indian Authors in Glaucoma Research}

Fifteen authors having been identified as most productive, who have published 20 and above papers in glaucoma research. The publications profile of these 15 authors along with their research output, citations received and h-index values are presented in Table 9. These 15 authors together contributed 534 papers with an average of 35.6 papers per author and account for $49.54 \%$ share in the cumulative Indian publications output during 2002-11. Five authors have published higher number of papers than the group average (150.07). These are: Ramanjit Sihota with 76 papers, followed by T. Dada (56 papers), R. George (47 papers), L. Vijaya (46 papers) and A.K. Mandal (41 papers). Considering the quality/impact of papers, these 15 productive authors have received a total of 2758 citations for 534 papers with an average of 5.16 citations per paper. Seven authors have registered higher impact than the average impact of papers of all authors (5.16). These are: M. Baskaran with 8.34 citations per paper, P.Raju (6.60 citations per paper), L. Vijaya (6.28 citations per paper), A.K. Mandal (5.93 citations per paper), R. George (5.72 citations per paper), V. Gupta (5.63 citations per paper), R. Parikh (5.50 Citations per Paper) and A.Gupta (5.24 citations per paper). Measuring the performance of these authors on the basis of $\mathrm{h}$ - index, seven authors have achieved the higher h-index value than the group average of 10.80. These authors are Ramanjit Sihota and A.K. Mandal with h-index of 15 each, followed by L. Vijaya and M. Baskaran (14), R. George (13), T. Dada and R.S. Parikh (11 each)(Table 9). 
Table 9. Productivity \& Citation Impact of India's Top Fifteen Authors in Glaucoma Research, 2002-11

\begin{tabular}{|c|c|c|c|c|c|c|}
\hline S.No & Name & Address & TP & TC & ACPP & $\begin{array}{c}\text { H- } \\
\text { Index }\end{array}$ \\
\hline 1 & Ramanjit Sihota & $\begin{array}{l}\text { All India Institute of Medical } \\
\text { Sciences, Dr Rajendra Prasad Center } \\
\text { for Ophthalmic Sciences, New Delhi }\end{array}$ & 76 & 319 & 4.20 & 15 \\
\hline 2 & T. Dada & $\begin{array}{l}\text { All India Institute of Medical } \\
\text { Sciences, Dr Rajendra Prasad Center } \\
\text { for Ophthalmic Sciences, New Delhi }\end{array}$ & 56 & 268 & 4.79 & 11 \\
\hline 3 & L. Vijaya & $\begin{array}{l}\text { Medical \& Vision Research } \\
\text { Foundation, Chennai }\end{array}$ & 46 & 289 & 6.28 & 14 \\
\hline 4 & R. George & 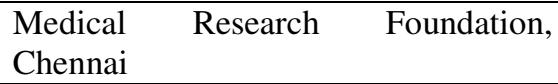 & 47 & 269 & 5.72 & 13 \\
\hline 5 & A.K. Mandal & L.V.Prasad Eye Institute, Hyderabad & 41 & 243 & 5.93 & 15 \\
\hline 6 & M. Baskaran & $\begin{array}{l}\text { Medical \& Vision Research } \\
\text { Foundation, Chennai }\end{array}$ & 32 & 267 & 8.34 & 14 \\
\hline 7 & V.Gupta & $\begin{array}{l}\text { All India Institute of Medical } \\
\text { Sciences, Dr Rajendra Prasad Center } \\
\text { for Ophthalmic Sciences, New Delhi }\end{array}$ & 30 & 169 & 5.63 & 8 \\
\hline 8 & S. Kaushik & $\begin{array}{l}\text { Post Graduate Institute of Medical } \\
\text { Education \& Research, Chandigarh }\end{array}$ & 25 & 118 & 4.72 & 9 \\
\hline 9 & A. Gupta & $\begin{array}{l}\text { Post Graduate Institute of Medical } \\
\text { Education \& Research, Chandigarh }\end{array}$ & 25 & 131 & 5.24 & 10 \\
\hline 10 & S.S. Pandav & $\begin{array}{l}\text { Post Graduate Institute of Medical } \\
\text { Education \& Research, Chandigarh }\end{array}$ & 27 & 85 & 3.15 & 9 \\
\hline 11 & P. Sony & $\begin{array}{l}\text { All India Institute of Medical } \\
\text { Sciences, Dr Rajendra Prasad Center } \\
\text { for Ophthalmic Sciences, New Delhi }\end{array}$ & 22 & 106 & 4.82 & 7 \\
\hline 12 & H.C. Agarwal & $\begin{array}{l}\text { All India Institute of Medical } \\
\text { Sciences, Dr Rajendra Prasad Center } \\
\text { for Ophthalmic Sciences, New Delhi }\end{array}$ & 25 & 73 & 2.92 & 9 \\
\hline 13 & R.S. Parikh & $\begin{array}{l}\text { Bombay City Eye Institute \& } \\
\text { Research Centre }\end{array}$ & 42 & 231 & 5.50 & 11 \\
\hline 14 & R. Saxena & $\begin{array}{l}\text { All India Institute of Medical } \\
\text { Sciences, Dr Rajendra Prasad Center } \\
\text { for Ophthalmic Sciences, New Delhi }\end{array}$ & 20 & 58 & 2.90 & 8 \\
\hline \multirow[t]{4}{*}{15} & P.Raju & $\begin{array}{l}\text { Medical \& Vision Research } \\
\text { Foundation, Chennai }\end{array}$ & 20 & 132 & 6.60 & 9 \\
\hline & & Total & 534 & 2758 & 5.16 & 10.8 \\
\hline & & Total of the Country & 1078 & & & \\
\hline & & $\begin{array}{l}\text { Share of Top 15Authors in Country } \\
\text { Output }\end{array}$ & $\begin{array}{c}49.5 \\
4\end{array}$ & & & \\
\hline
\end{tabular}

\section{Research Communication in High Productive Journals}

The 15 most productive journals publishing Indian research papers in glaucoma research together contributed 533 papers, which accounts for $49.44 \%$ share of the world total output during 2002-11. The cumulative publications output share of these 15 most productive journals showed a decrease in world's publications output from $59.20 \%$ during 2002-06 to $43.12 \%$ during 2007-11 (Table 10) 
Table 10. Media of Communication in India Glaucoma Research, 2002-11

\begin{tabular}{|l|l|c|c|c|}
\hline \multirow{2}{*}{ S.No } & \multirow{2}{*}{ Name of the Journal } & \multicolumn{3}{|c|}{ Number of Papers } \\
\cline { 3 - 5 } & & $2002-06$ & $2007-11$ & $2002-11$ \\
\hline 1 & Indian Journal of Ophthalmology & 64 & 82 & 146 \\
\hline 2 & Eye & 23 & 31 & 54 \\
\hline 3 & Journal of Glaucoma & 12 & 24 & 36 \\
\hline 4 & Journal of Cataract and Refractive Surgery & 17 & 17 & 34 \\
\hline 5 & Ophthalmology & 12 & 22 & 34 \\
\hline 6 & British Journal of Ophthalmology & 17 & 13 & 30 \\
\hline 7 & Clinical and Experimental Ophthalmology & 16 & 11 & 27 \\
\hline 8 & Asian Journal of Ophthalmology & 13 & 15 & 28 \\
\hline 9 & Molecular Vision & 12 & 14 & 26 \\
\hline 10 & Investigative Ophthalmology \& Visual Science & 13 & 13 & 26 \\
\hline 11 & European Journal of Ophthalmology & 9 & 13 & 22 \\
\hline 12 & Cornea & 8 & 11 & 19 \\
\hline 13 & Annals of Ophthalmology & 18 & 0 & 18 \\
\hline 14 & Journal of the Indian Medical Association & 10 & 7 & 17 \\
\hline 15 & Archives of Ophthalmology & 7 & 9 & 16 \\
\hline & Total & 251 & 282 & 533 \\
\hline & Total of the India & 424 & 654 & 1078 \\
\hline & Share of top 15 journals in Indian output & 59.2 & 43.12 & 49.44 \\
\hline
\end{tabular}

\section{Summary}

India has published 1078 papers in glaucoma research during 2002-11, which has increased from 61 papers in 2002 to 207 papers in 2011, witnessing an annual average growth rate of 18.29\%. In terms of impact and citation quality, the average citation per paper registered by Indian publication output was 3.03 during 2002-11, which has decreased from 3.87 during 2002-06 to 2.48 during 2007-11. Among the top 15 most productive countries in glaucoma research during 2002-11, the United States tops the list, with a share of $27.25 \%$ during $2002-11$, followed by China ( $8.60 \%$ share), U.K. (8.09\% share), Japan (6.75\% share), Germany (6.36\% share), etc. India is ranked at $6^{\text {th }}$ position among the top 20 most productive countries in glaucoma research, with its global publication share of 3.26\% during 2002-11. India's global publications share increased from 3.00\% during 2002-06 to 3.45\% during 2007-11. The international collaborative papers share of India in glaucoma research was $21.06 \%$ during 2002-11, which has increased from $17.92 \%$ during 2002-06 to 23.09\% during 2007-11. In all 45 countries participated in international collaboration with India in glaucoma research during 2002-11.The largest contribution to international collaborative 
papers of India in glaucoma research comes from United States (with 50.22\% share), followed by UK (21.59\% share), Singapore (7.05\% share), Germany (5.29\% share), Italy (3.08\% share), Brazil (2.64\% share), Netherlands (3.08\% share), China (2.64\% share), Israel (2.20\% share), Japan (2.20\% share), Canada, Malaysia and Switzerland (1.76\% share each) and Nepal (1.32\% share).

Among different types of glaucoma research in India during 2002-11, the largest contribution $(19.85 \%$ share) comes from open angle glaucoma, followed by closed angle glaucoma (13.17\% share), congenital glaucoma ( $8.53 \%$ share), normal tension glaucoma ( $7.14 \%$ share), secondary glaucoma $(5.01 \%$ share), neovascular glaucoma (2.69\% share), traumatic glaucoma (1.11\% share), pigmentary glaucoma $(0.46 \%$ share), pseudoexfoliative glaucoma ( $0.19 \%$ share) and Irido Corneal Endothelial syndrome ( $0.09 \%$ share). The maximum focus of Indian glaucoma research in terms of research output during 2002-11 was on adults (with $50.00 \%$ share), followed by middle aged (27.83\% share), adolescents (14.10\% share), child (12.62\% share) and aged $80 \&$ over (7.14\% share). Among the subfield wise distribution of world glaucoma research during 2002-11, the largest contribution (88.03\% share) comes from medicine, followed by pharmacology, toxicology \& pharmaceutics (10.85\% share), neurosciences (9.83\% share), biochemistry, genetics \& molecular biology (5.47\% share) and health profession (1.39\% share). The top 15 most productive Indian institutions involved in glaucoma research have together contributed $66.42 \%$ share in the cumulative Indian publications output, with an average of 47.73 papers per institution. The average citation per paper and h-index registered by the total papers of these 15 institutions was 3.55 and 8.80 during 200211.The 15 most productive Indian authors together contributed $49.54 \%$ share in the cumulative Indian publications output during 2002-2011, with an average of 35.6 papers per author. The average citation per paper and h-index registered by the total papers of these 15 authors was 5.16 and 10.80 during 2002-11. The 15 most productive journals publishing world research papers in glaucoma research together accounts for $49.44 \%$ share of the total world output during 2002-11, which decreased from 59.20\% during 2002-06 to $43.12 \%$ during $2007-11$

With around 12 million people affected by glaucoma in India, we have produced only 1078 research papers during the last ten years. It means the research efforts needs to be strengthened quiet substantially by way of investment in R\&D. Both research output and quality of research should be increased and strengthened and international collaborative research may further be widened to learn from the experiences of other countries. The glaucoma's irreversibility, lacking of glaucoma specialists and patients unawareness demand for an economic and effective glaucoma diagnosis system for screening. Disease control and elimination require an adequately trained functional workforce with an enabling infrastructure and technology. Population awareness of the disease is low and most patients attending eye clinics do not receive a routine comprehensive eye examination that is required to detect glaucoma (and other potentially blinding eye diseases). Such a routine is not taught or practiced by the majority of training institutions either. Glaucoma cannot be managed in isolation. The objective should be to detect and manage all 
potential causes of blindness and prevention of blindness from glaucoma should be integrated into existing programs. The routine of comprehensive eye examination in every clinic and its teaching (and use) in residency programs should be mandatory for the detection and management of potentially preventable blinding pathology from any cause, including glaucoma. The author suggests the need to develop eye care facilities in every district, to develop human resources for providing eye care services, to improve the quality of service delivery and to secure participation of voluntary organization in eye care

\section{References}

1. US Library of Medicine. PubMed Health.Fact sheet: Glaucoma. July 5, 2012. http://www.ncbi.nlm.nih.gov/pubmedhealth/PMH0048141/ (Accessed on October 2, 2012).

2. Glaucoma Research Foundation. Type of Glaucoma. http://www.glaucoma.org/glaucoma/typesof-glaucoma.php. (Accessed on October 2, 2012).

3. Glaucoma Research Foundation. Other Type of Glaucoma. http://www.glaucoma.org/glaucoma/other-types-of-glaucoma.php (Accessed on October 2, 2012)

4. http://www.dnaindia.com/health/report_glaucoma-silently-blights-light-in-the-eyes_1519673 (Accessed on September 6, 2012)

5. Study of Glaucoma Treatment in India Completed. Cure glaucoma Winter 2006. http://www.hopkinsmedicine.org/wilmer/news/cureglaucoma/cure_glaucoma_W06.pdf. (Accessed on September 6, 2012)

6. Glaucoma silently blights light in the eyes. Mar 14, 2011. http://articles.timesofindia.indiatimes.com/ 2011-04-18/pune/29443049_1_glaucoma-mutationsgene-therapy. (Accessed on September 6, 2012)

7. Glaucoma Society of India. http://www.glaucomaindia.com/ (Accessed on September 28, 2012)

8 Davis, M., Wilson, C.S. \& Hood, W.W. Ophthalmology and optics: An informetric study of Australia's contribution to fields in the vision science domain, 1991-95. Scientometrics 1999, 46(3), 399-416

9. Zou, Feng, Wu, Mingxing and Wu, Kaili. Outcomes associated with ophthalmology, optometry and visual science literature in the Science Citation Index from mainland China, 2000-2007. Scientometrics 2009; 81 (12):671-682.

10. Kumaragurupari, R, Sieving, Pamela C and Lalitha, Prajna. A bibliometric study of publications by Indian ophthalmologists and vision researchers, 2001-06. Indian Journal of Ophthalmology 2010, 58 (4), 275-280. 
11. Consoli, David and Ramgopalan. Pattern of organization in the development of medical knowhow: The case of glaucoma research. INGENIO (SIC-UPN) Polytechnic University of Valencia, Spain (Working Paper Number 2010/06). 